\title{
Reassessment of treadmill stress testing for risk stratification in patients with acute myocardial infarction treated by thrombolysis
}

\author{
Robert Stevenson, Velaitham Umachandran, Kulasegaram Ranjadayalan, Paul Wilkinson, \\ Bradley Marchant, Adam D Timmis
}

\begin{abstract}
Objectives-To evaluate the role of a treadmill stress test for identifying patients at risk of recurrent ischaemic events after acute myocardial infarction treated by thrombolysis.
\end{abstract}

Background-The natural history of myocardial infarction has changed with the introduction of thrombolytic treatment; there is a lower mortality but a higher incidence of recurrent thrombotic events (reinfarction, unstable angina). The treadmill stress continues to be recommended for risk stratification after acute myocardial infarction even though its value has never been formally reassessed in the thrombolytic era.

Methods-Prospective observational study in which 256 consecutive patients who presented with acute myocardial infarction treated by thrombolysis underwent an early treadmill stress test and were followed up for 10 (range 6-12) months.

Results-Recurrent ischaemic events occurred in 41 patients (unstable angina 15 , reinfarction 21 , death five) and a further 21 required revascularisation. Both ST depression at a low workload and low exercise tolerance ( $<7$ metabolic equivalents of the task (METS) were predictive of recurrent events, with respective hazard ratios of 1.93 (95\% confidence interval $(95 \% \mathrm{CI}) 1 \cdot 17-3 \cdot 20 ; \mathrm{p}<0.01))$ and $1.67(95 \%$ CI 1.0-2.78; $p<0.05)$. These variables identified $50 \%$ and $70 \%$ of patients who subsequently sustained a recurrent ischaemic event, but the corresponding values for positive predictive accuracy were only $26 \%$ and $21 \%$. Thus they are of limited value as a screening measure for identifying patients likely to benefit from invasive investigation and revascularisation. None of the other variables (ST elevation, haemodynamic responses, ventricular extrasystoles, angina) was significantly associated with recurrent ischaemic events.

Conclusions-The treadmill stress test is of limited value for identifying patients at risk of recurrent ischaemic events after acute myocardial infarction treated by thrombolysis.

(Br Heart f 1993;70:415-420)
Thrombolytic treatment has favourably influenced the natural history of myocardial infarction by reducing mortality in hospital and during early follow up. ${ }^{1-3}$ Despite reductions in mortality, however, the incidence of recurrent thrombotic events (reinfarction, unstable angina) has increased, and there is now an important need for non-invasive tests to identify those patients at greatest risk. ${ }^{3-6}$ The treadmill stress test continues to be recommended for this purpose even though its value has never been formally reassessed in the thrombolytic era. ${ }^{7}$ The reassessment of the treadmill stress test is necessary because the determinants of recurrent ischaemic events after myocardial infarction have changed with the introduction of thrombolytic treatment. Previously, risk was largely related to left ventricular dysfunction and a propensity to ventricular arrhythmias, as well as to remote ischaemia in patients with multivessel disease. Now, however, many of the recurrent events that occur early after myocardial infarction are the result of coronary re-occlusion in patients who have previously been treated successfully by thrombolysis. ${ }^{89}$ It cannot be assumed, therefore, that the treadmill stress test remains a valid means of identifying high risk patients in the thrombolytic era. ${ }^{10}$ In our study we have undertaken a prospective reassessment of an early treadmill stress test for risk stratification after acute myocardial infarction. It comprises a large series of patients from a district general hospital all of whom received thrombolytic treatment.

\section{Methods}

SELECTION OF PATIENTS

The study group comprised 256 consecutive patients who presented to Newham General Hospital with acute myocardial infarction and were treated by thrombolysis. Table 1 shows the characteristics of patients. The chosen sample size provided $90 \%$ power for detecting an association between exercise test variables and recurrent ischaemic events with a relative risk of 2 . The diagnosis of acute myocardial infarction was based on any two of the following three criteria: typical chest pain, $\geqslant 0.1 \mathrm{mV} S \mathrm{~S}$ elevation in at least one standard or two precordial leads, a rise in serum creatine kinase activity to $\geqslant 400 \mathrm{IU} / / 1$. Most patients were treated with streptokinase (1.5 million IU infused over one hour) but, 
Table 1 Clinical characteristics of the study group

\begin{tabular}{ll}
\hline Characteristic & Value \\
\hline Age (mean (SD) (range) yr) & $57(9)(33-79)$ \\
Sex (n): & \\
$\quad$ Men & 218 \\
$\quad$ Women & 38 \\
Site of infarction (n): & \\
$\quad$ Anterior & 131 \\
$\quad$ Inferior & 125 \\
Q Wave infarction (n): & \\
Q wave & 203 \\
$\quad$ Non-Q wave & 53 \\
\hline
\end{tabular}

because we were participating in the multicentre international study of infarct survival III (ISIS III) during part of the recruitment period, 40 patients were treated with either streptokinase $(1.5$ million IU infused over one hour), or duteplase (100 mg infused over four hours), or anistreplase (30 IU injected over three minutes), depending on the randomisation. Specific inclusion criteria were: (a) acute myocardial infarction as defined; (b) treatment with a thrombolytic agent: (c) uncomplicated hospital course without ongoing chest pain, electrical instability, or heart failure; (d) ability to perform a symptom limited treadmill exercise test; (e) no abnormalities preventing interpretation of the exercise electrocardiogram (left bundle branch block, paced rhythms, digoxin induced ST/T changes).

\section{Selection of patients for cardiac catheterisation}

At the time of the study coronary arteriography was offered to all patients under the age of 70 as routine clinical practice and was performed on 200. Reasons for not proceeding to arteriography in the remaining 56 patients included age $>70$ (31) and refusal to give consent (15); in the rest the reason was not recorded. Revascularisation was offered to patients with prognostically important three vessel disease and to those with limiting angina despite medical treatment.

\section{EXERCISE TEST}

A symptom limited treadmill test (modified Bruce protocol) was performed before or soon after discharge from hospital, seven to 21 days after infarction. Patients exercised for periods of three minutes stages at progressively increasing workloads. Electrocardiograms were recorded before exercise, at the end of each work load and at peak exercise. Significant ST depression during the stress test was defined as horizontal or down sloping ST depression $\geqslant 0.1 \mathrm{mV}$ below the resting level measured 0.08 seconds after the J point. Significant ST elevation was defined as $\geqslant 0 \cdot 1 \mathrm{mV}$ elevation above the resting level measured at the J point.

\section{MEDICATION}

All patients were prescribed $150 \mathrm{mg}$ aspirin daily, and other cardiac medications as indicated. $\beta$ Blockers were prescribed in 84 patients according to the policy of the physician in charge of the individual patient, and were not withdrawn before the stress test.

FOLLOW UP

All patients were followed up either by telephone interview or formal review in a clinic, and details of hospital readmissions were then obtained from review of the case notes. The end points recorded were: cardiac death, myocardial infarction, unstable angina, coronary artery bypass surgery, and coronary angioplasty. The diagnostic criteria for reinfarction were the same as for entry into the study. Unstable angina was defined as prolonged cardiac chest pain associated with acute electrocardiogram changes but without a significant rise in cardiac enzymes, that required urgent admission to the coronary care unit. For analytical purposes ischaemic events occurring after revascularisation were not included.

\section{STATISTICAL ANALYSIS}

Statistical analysis was undertaken in conjunction with the Epidemiology Research Unit at the London Chest Hospital. All averaged values are expressed as means (SD). The distribution of discrete variables between groups was compared by the $\chi^{2}$ test. The clinical value of the exercise stress test was assessed by determining sensitivity, specificity, and positive and negative predictive accuracy. Sensitivity (true positive divided by true positive plus false negative) is the proportion of patients with a recurrent ischaemic event who are correctly identified by the exercise stress test. Specificity (true negative divided by true negative plus false positive) is the proportion of patients without events who are correctly identified by the test. Positive predictive accuracy (true positive divided by true positive plus false positive) is the proportion of patients with a positive test who sustain an event. Negative predictive accuracy (true negative divided by true negative plus false negative) is the proportion of patients with a negative test who do not sustain an event. Cardiac event free probability was estimated by the Kaplan-Meier method ${ }^{11}$ and comparison of cardiac event free curves by the log rank test ${ }^{12}$ with the EGRET (Epidemiological Graphics, Estimation, and Testing, version $0 \cdot 26 \cdot 1$ ) and BMDP (1990 release) statistical software packages.

The study was approved by the local ethics committee, and all patients gave written informed consent.

\section{Results}

RECURRENT ISCHAEMIC EVENTS DURING EARLY FOLLOW UP

Follow up data are available for all 256 patients 10 (range: 6-12) months after discharge from hospital. During this period there were 41 acute ischaemic events (hard events) - namely unstable angina (15), acute myocardial infarction (21), and sudden death (5). A further nine patients underwent coronary artery bypass surgery either because of 
Table 2 Relation between treadmill stress test variables and hard events

\begin{tabular}{lllll}
\hline Variable & $\begin{array}{l}\text { No event } \\
(n=215) \\
n(\%)\end{array}$ & $\begin{array}{l}\text { Event } \\
(n=41) \\
n(\%)\end{array}$ & $\chi^{2}$ & $p$ Values \\
\hline ST depression all $(\mathrm{n}=126)$ & $101(47)$ & $25(61)$ & $3 \cdot 16$ & $<0 \cdot 10$ \\
ST depression low workload $(\mathrm{n}=78)$ & $58(27)$ & $20(49)$ & $8 \cdot 07$ & $<0 \cdot 01$ \\
ST elevation (n=101) & $80(37)$ & $21(51)$ & $3 \cdot 46$ & $<0 \cdot 1$ \\
Workload <7 METS $(\mathrm{n}=135)$ & $107(50)$ & $28(68)$ & $4 \cdot 98$ & $<0 \cdot 05$ \\
Blood pressure <30 mm Hg $(\mathrm{n}=97)$ & $79(37)$ & $18(44)$ & $0 \cdot 75$ & NS \\
Change in double product <10 000 $(\mathrm{n}=113)$ & $96(45)$ & $17(41)$ & $0 \cdot 09$ & NS \\
Ventricular arrhythmia $(\mathrm{n}=57)$ & $47(22)$ & $10(24)$ & $0 \cdot 14$ & NS \\
Angina $(\mathrm{n}=55)$ & $49(23)$ & $6(15)$ & $1 \cdot 20$ & NS \\
Abnormal test $(\mathrm{n}=194)$ & $160(74)$ & $34(83)$ & $1 \cdot 33$ & NS \\
\hline
\end{tabular}

Table 3 Relation between treadmill stress test variables and all events

\begin{tabular}{lclll}
\hline Variable & $\begin{array}{l}\text { No event } \\
(n=194) \\
n(\%)\end{array}$ & $\begin{array}{l}\text { Event } \\
(n=62) \\
n(\%)\end{array}$ & $\chi^{2}$ & $p$ Values \\
\hline ST depression all $(\mathrm{n}=126)$ & $90(46)$ & $36(58)$ & $2 \cdot 35$ & NS \\
ST depression low workload $(\mathrm{n}=78)$ & $49(25)$ & $29(47)$ & $9 \cdot 63$ & $<0 \cdot 01$ \\
ST elevation (n=101) & $71(37)$ & $30(48)$ & $2 \cdot 83$ & $<0 \cdot 1$ \\
Workload <7 METS $(\mathrm{n}=135)$ & $94(48)$ & $41(66)$ & $5 \cdot 44$ & $<0 \cdot 05$ \\
Blood pressure <30 mm Hg (n=97) & $70(36)$ & $27(44)$ & $0 \cdot 88$ & NS \\
Ghange in double product <10 000 (n=113) & $86(44)$ & $27(44)$ & $0 \cdot 01$ & NS \\
Ventricular arrhythmia $(\mathrm{n}=57)$ & $46(24)$ & $11(18)$ & $1 \cdot 04$ & NS \\
Angina $(\mathrm{n}=55)$ & $39(20)$ & $16(26)$ & 0.90 & NS \\
Abnormal test $(\mathrm{n}=194)$ & $144(74)$ & $50(81)$ & 1.18 & NS \\
\hline
\end{tabular}

limiting angina or prognostically important three vessel disease, and 12 patients underwent coronary angioplasty for limiting angina. Thus 62 patients either sustained an ischaemic event or underwent revascularisation (all events).

\section{END POINTS OF EXERCISE TEST}

The treadmill stress test was discontinued because of fatigue in 211 patients, angina in 29 patients, and considerable ST depression $(>3 \mathrm{~mm})$ in 16 patients. No treadmill test was discontinued because of a fall in systolic blood pressure or because of ventricular arrythmia.

\section{VARIABLES OF TREADMILL STRESS TEST AND RECURRENT ISCHAEMIC EVENTS \\ ST segment depression}

Exercise induced ST depression was seen in $126(49 \%)$ patients. It occurred at a low workload ( 7 metabolic equivalents of the task (METs) in $78(30 \%)$ patients (table 2). Although exercise induced ST depression occurred more often in patients with recurrent events the association was only statistically significant when ST depression occurred at a low workload. Thus ST depression at a low workload occurred in $49 \%$ of patients who sustained a hard event compared with $27 \%$ of those who did not $(p<0.01)$. The

Table 4 Diagnostic value of selected variables from the treadmill stress test for predicting recurrent ischaemic events with and without revascularisation taken into account as an end point

\begin{tabular}{lllll}
\hline & Sensitivity & Specificity & $\begin{array}{l}\text { Positive } \\
\text { predictive } \\
\text { accuracy }\end{array}$ & $\begin{array}{l}\text { Negative } \\
\text { predictive } \\
\text { accuracy }\end{array}$ \\
\hline ST depression & $63(58)$ & $53(53)$ & $20(29)$ & $88(80)$ \\
ST depression low workload & $50(47)$ & $73(74)$ & $26(37)$ & $89(81)$ \\
Workload <7 METS & $70(65)$ & $49(52)$ & $21(30)$ & $89(82)$ \\
Abnormal test & $83(81)$ & $25(26)$ & $17(26)$ & $89(81)$ \\
\hline
\end{tabular}

Values are percentages and relate to hard events (all events in parentheses). relation was $50 \%$ sensitive and $73 \%$ specific for hard events, and was associated with positive and negative predictive accuracies of $26 \%$ and $89 \%$. Similar results were obtained when all events were taken into account (table 4).

\section{ST segment elevation}

Exercise induced ST elevation was seen in 101 (39\%) patients. It occurred more commonly in patients with recurrent ischaemic events than those without, but the association was not significant.

\section{Exercise tolerance}

The median workload reached during the treadmill stress test was 7 METs. Patients who did not reach this workload had a significantly higher incidence of recurrent ischaemic events than those who reached a workload of $\geqslant 7$ METs ( $68 \%$ v 50\%; $\mathrm{p}<0.05)$.

\section{Haemodynamic response}

The median rise in systolic blood pressure during exercise was $30 \mathrm{~mm} \mathrm{Hg}$. The 97 patients who did not reach the median blood pressure response did not have a significantly higher rate of recurrent ischaemic events. Similarly, failure to reach the median value for exercise induced change in double product (heart rate $\mathrm{x}$ systolic blood pressure) was not associated with recurrent ischaemic events.

\section{Ventricular extrasystoles}

Ventricular extrasystoles occurred in 57 patients during exercise. In every case the extrasystolic beats were isolated and ventricular tachycardia did not occur. There was no relation between exercise induced extrasystoles and recurrent ischaemic events.

\section{Symptoms}

Only 55 patients experienced angina during the treadmill test. There was no association between exercise induced angina and recurrent ischaemic events, regardless of whether revascularisation was included as an ischaemic end point.

\section{Abnormal test}

The stress test was defined as being abnormal when any of the following occurred; ST depression; less than the median workload was reached; impaired haemodynamic response: ventricular extrasystole; exertional angina. Thus $194(76 \%)$ patients had an abnormal stress test, but there was no significant relation between an abnormal test and recurrent events. Although the presence of an abnormal stress test was associated with $83 \%$ sensitivity for recurrent ischaemic events, specificity was $25 \%$ and positive predictive accuracy was $17 \%$. The negative predictive accuracy of a normal stress test was $89 \%$.

\section{EVENT FREE SURVIVAL ANALYSIS}

Event free survival analysis with the log rank test showed that both ST depression at a low workload and low exercise tolerance $(<7$ METs) were predictive of recurrent events 


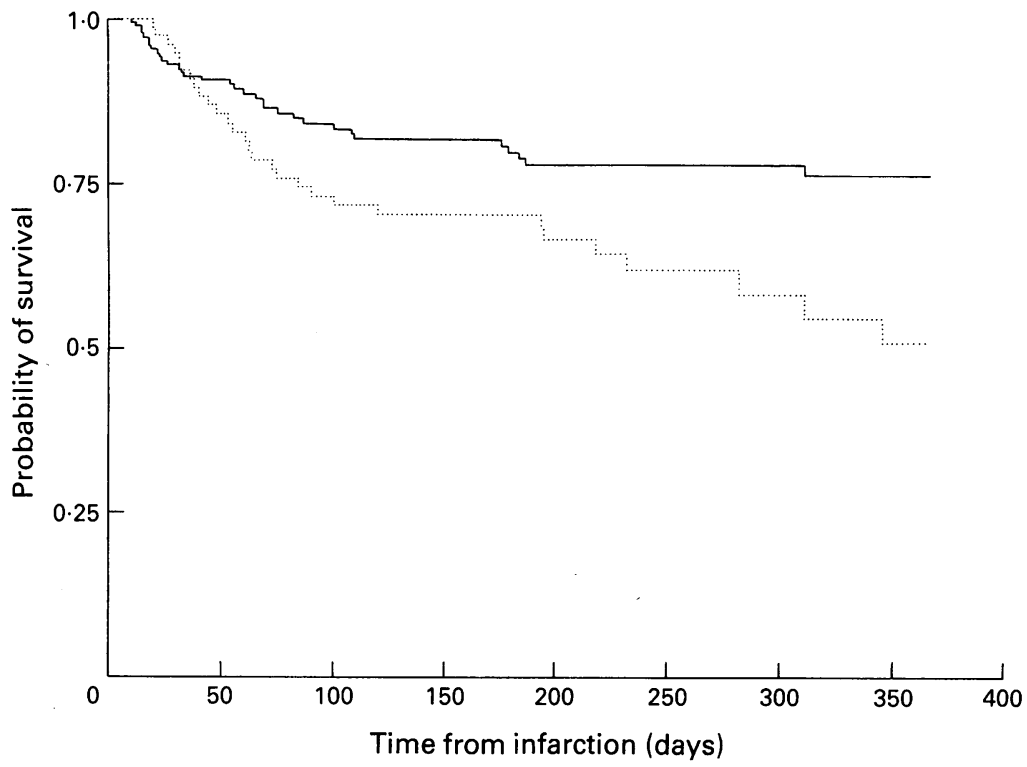

Figure 1 Kaplan-Meier event free survival curves for patients with (broken line) and without ST depression at low workload. Relative hazard ratio for ST depression at low workload was 1.93 (95\% CI 1.17 to $3.20 ; p<0.01)$.

(figs 1 and 2); hazard ratios were 1.93 $(95 \% \mathrm{Cl} 1 \cdot 17-3 \cdot 20 ; \mathrm{p}<0.01)$ and $1.67(95 \%$ $\mathrm{Cl} 1 \cdot 0-2 \cdot 78 ; \mathrm{p}<0.05)$.

\section{Discussion}

EXERCISE-INDUCED ST DEPRESSION

The identification of patients at risk of recurrent ischaemic events after myocardial infarction is recognised as an important management priority. In the past a treadmill stress test has been widely used for this purpose, but our results indicate that it is of limited value for risk stratification in the thrombolytic era. Despite a significant rela-

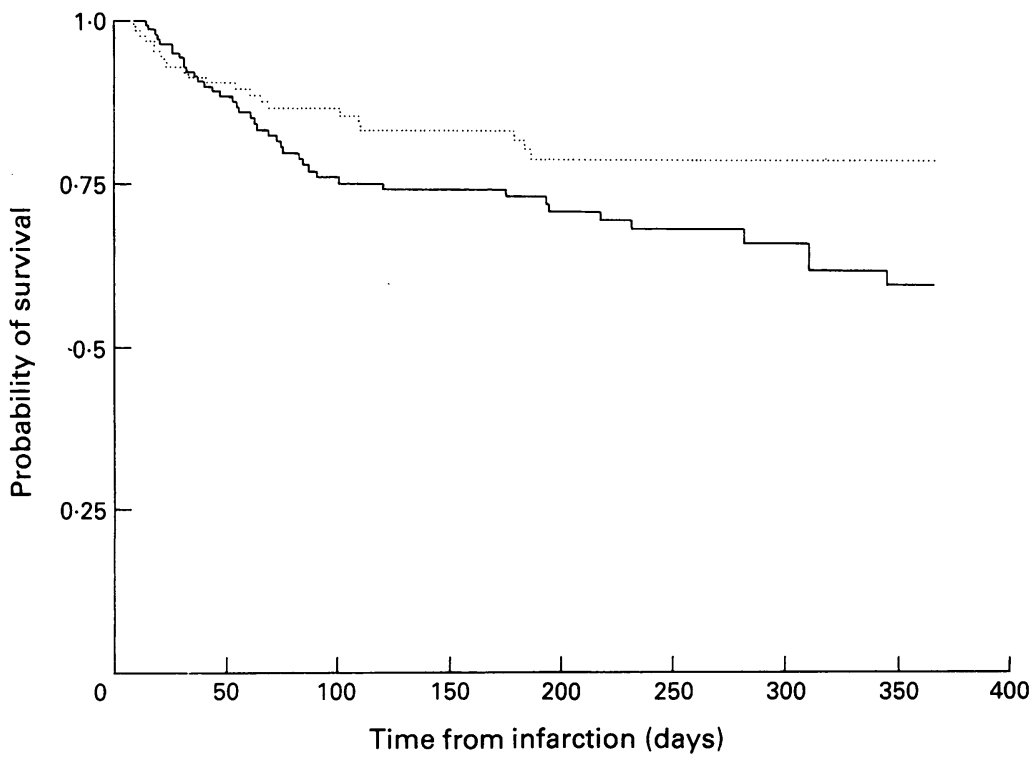
Figure 2 Kaplan-Meier event free survival curves comparing patients who reached a
workload of $\geqslant 7$ METs (broken line) with those who did not (continuous line). Relative hazard ratio for failure to achieve a workload of 7 METs was 1.67 (95\% CI 1.0 to 2.78 ; $p<0.05)$. tion between ST depression at low workload and recurrent ischaemic events, the values obtained for sensitivity and positive predictive accuracy indicate a limited role in clinical practice. In particular, its clinical value as a method of screening for patients at high risk is limited by its modest sensitivity. Thus a positive test on the basis of ST depression at low workload only identified $50 \%$ of patients who had a recurrent ischaemic event. Furthermore, the low positive predictive accuracy is important if the test is used to select patients for potential revascularisation, as many patients would be subjected to unnecessary invasive investigation on the basis of a positive result. The negative predictive accuracy ( $89 \%)$, on the other hand, is high and a negative response clearly identifies a group of patients at low risk.

\section{OTHER VARIABLES OF THE EXERCISE STRESS} TEST

Other variables apart from ST segment changes may have prognostic implications early after acute myocardial infarction. In our study, patients who reached a workload of $<7$ METs were also at greater risk of recurrent ischaemic events although, like ST depression, the association is likely to be of limited value in clinical practice. Patients with impaired exercise tolerance include those limited by severe left ventricular dysfunction as well as those with continuing ischaemia. Severe left ventricular dysfunction, although associated with sudden death, is not necessarily predictive of recurrent ischaemic events. ${ }^{13}$ Thus in this study of patients treated by thrombolysis (in whom mortality was relatively low) reduced exercise tolerance was associated with a lower hazard ratio and was less specific for recurrent events than ST depression at low workload. Similarly, exercise induced ST elevation, impaired haemodynamic responses, and ventricular extrasystole were not predictive of recurrent events, a finding consistent with their known association with extensive myocardial injury rather than reversible ischaemia ${ }^{14-16}$ The classification of the stress test as normal or abnormal by taking all the treadmill variables into account was not particularly helpful. Although an abnormal test was associated with $83 \%$ sensitivity for recurrent events, it was non-specific and had poor positive predictive accuracy. Only $24 \%$ of patients had a normal test by these criteria and the negative predictive accuracy was no greater than that obtained with more specific variables such as ST depression at a low workload.

INFLUENCE OF THROMBOLYSIS ON THE VALUE OF A POST INFARCTION EXERCISE STRESS TEST The reasons for the modest value of a treadmill stress test in identifying high risk patients may relate to the influence of thrombolysis on determinants of recurrent ischaemic events. Before the thrombolytic era, the value of a treadmill stress test for prognostic assessment was largely dependent on its ability to identify remote ischaemia associated with multivessel 
disease and severe left ventricular dysfunction. With the introduction of thrombolytic treatment however, mortality after hospital discharge has fallen (presumably reflecting a reduction in size of infarction) but the risk of other ischaemic events has increased. ${ }^{3-6} \mathrm{By}$ recanalising the infarct related artery, thrombolytic treatment exposes the patient to the potential risk of coronary reocclusion. ${ }^{28917} \mathrm{It}$ may therefore be unreasonable to expect the treadmill stress test, a dynamic test for reversible ischaemia and severe left ventricular dysfunction, to be predictive of sudden thrombotic occulusion particularly as this may be independent of the severity of stenosis. ${ }^{18} 19$

\section{POST INFARCTION EXERCISE STRESS TEST IN THE PRETHROMBOLYTIC ERA}

Although this study casts doubt on the clinical value of a stress test early after thrombolytic treatment, it is noteworthy that even before the thrombolytic era its role for prognostic assessment was controversial. Thus although a number of studies have shown exertional ST depression to be predictive of multivessel disease, ${ }^{2021}$ reinfarction ${ }^{22} 23$ and mortality, ${ }^{23} 24$ these findings have not been confirmed by other investigators. ${ }^{25-27}$ Reasons for this are unclear but are likely to be multifactorial reflecting differences in selection criteria, sample size, choice of end points, and criteria adopted for a positive test. Exercise test variables most often associated with subsequent mortality have been those that relate to severe left ventricular dysfunction (ST elevation, exercise time, ventricular extrasystole) ${ }^{142829}$ and only when soft endpoints (recurrent angina, need for coronary bypass surgery) have been included has an exercise test been found to be consistently predictive of recurrent ischaemic events. ${ }^{283031}$ As previously discussed, the task of a non-invasive test in the thrombolytic era must be primarily directed at identifying those patients at risk of coronary reocclusion and not only those with extensive infarction or remote ischaemia.

\section{LIMITATIONS OF THE STUDY}

The interpretation of studies of this kind is inevitably confounded by the proportion of patients who undergo revascularisation. As revascularisation is an elective procedure rather than a potentially preventable ischaemic event it may or may not be appropriate to include it as an end point in event free survival analysis. Thus, whereas there is no clinical necessity to identify patients who may require revascularisation in the future, its exclusion as an end point effectively excludes from the analysis those patients who may have been at high risk if treated conservatively. In our study, however, the relation between a stress test and outcome was evaluated with and without revascularisation included as an end point, and there was no major difference between the two analyses. Importantly, patients were not selected for coronary arteriography, and hence potentially for revascularisation, on the basis of findings from the stress test, and therefore outcome was not directly influenced by the result of the stress test itself.

The second potential limitation relates to the choice of end points. In our study, a number of clinical end points have been combined for the purposes of statistical analysis. Although this is common practice in observational studies of this kind, ideally end points should only be combined if they reflect similar underlying pathological mechanisms. Sudden death was included as an ischaemic event despite the possibility that some of these deaths may have been primarily arrhythmic in aetiology. The number of sudden deaths were, however, low compared with the total number of events, and therefore a separate analysis of the relation between a stress test and sudden death would not have been meaningful.

Finally, $\beta$ blockers were prescribed in $33 \%$ of patients and were not withdrawn before the stress test. Arguably this may have influenced the results of the study, although there is little information available regarding the effects of $\beta$ blockers on the diagnostic value of a post-infarction stress test. Certainly $\beta$ blockers have not always been withdrawn before a stress in previous studies, including those in which the results of the test were strongly predictive of outcome..$^{242}$

In conclusion, patients with acute myocardial infarction treated by thrombolysis have a high incidence of recurrent ischaemic events after discharge from hospital. The modest diagnostic capabilities of an early treadmill stress test for identifying accurately this high risk group emphasises the limitations of this technique for selecting patients in need of further investigation and revascularisation. Although selected stress test variables such as ST depression at a low workload and impaired exercise capacity may be of some value for risk stratification, there remains an important need to evaluate other non-invasive methods for this purpose.

1 Second International Study of Infarct Survival, Collaborative Group. Randomised trial of intravenous Collaborative Group. Randomised trial of intravenous
streptokinase, oral aspirin, both, or neither among streptokinase, oral aspirin, both, or neither among 17187 cases of suspected acute
ISIS-2. Lancet 1988;ii:349-60.

2 Simoons ML, Serruys PW, Brand M. Improved survival after early thrombolysis in acute myocardial infarction. Lancet 1985;ii:57-82.

3 Gruppo Italiano per lo Studiodella Streptochi-Nas nell'infarto Miocardico. Long term effects of intravenous thrombolysis in acute myocardial infarction: final report of the GISSI study. Lancet 1987;ii: 871-5.

4 Simoons ML, Vos J, Tijssen JGP, et al. Long-term benefit of benefit of early thrombolytic therapy in patients with acute myocardial infarction: 5 year follow-up of a trial acute myocardial infarction: 5 year follow-up of a trial
conducted by the Interuniversity Cardiology Institute of conducted by the Interuniversity Cardiology Institute of
the Netherlands. F Am Coll Cardiol 1989;14:1609-15.

5 Feit F, Mueller HS, Braunwald E, et al and the TIMI research group. Thrombolysis in myocardial infarction (TIMI) phase II trial: outcome comparison of a "conservative strategy" in community versus tertiary hospitals. F Am Coll Cardiol 1990;16:1529-34.

6 SWIFT (should we intervene following thrombolysis?) Trial Study Group. SWIFT trial of delayed elective intervention v conservative treatment after thrombolysis with anistreplase in acute myocardial infarction. $\mathrm{Br} \mathrm{Med}$ f 1991;302:555-60.

7 The Thrombolysis in Myocardial Infarction Study Group Comparison of invasive and conservative strategies afte treatment with intravenous tissue plasminogen activator in acute myocardial infarction. Results of the thrombolysis in myocardial infarction (TIMI) phase II trial. N Engl $\mathcal{F}$ Med 1989;320:618-27. 
8 Harrison DG, Ferguson DW, Collins SM, et al. Rethrombosis after reperfusion with streptokinase: importance of geometry of residual lesions. Circulation 1984;69:991-9.

9 Williams DO, Borer J, Braunwauld E, et al. Intravenous recombinant tissue-type plasminogen activator in patients with acute myocardial infarction. A report from the NHLBI thrombolysis in myocardial infarction trial. Circulation 1986;73:338-46.

10 Lavie CJ, Gibbons RJ, Zinsmeister AR, Gersh BJ. Interpreting results of exercise studies after acute myocardial infarction altered by thrombolytic therapy, coronary angioplasty or bypass. Am $\mathcal{F}$ Cardiol 1991; 67:116-20.

11 Kaplan EL, Meier P. Non-parametric estimation from incomplete observations. Fournal of the American Statistical Association 1958.53:457.

12 Mantel N. Evaluation of survival data and two new rank order statistics arising in its consideration. Cancer Chemother Rep 1966;50:163.

13 Mueller HS, Cohen LS, Braunwald E, et al. Predictors of early morbidity and mortality after thrombolytic therapy of acute myocardial infarction. Analysis of patient subgroups in the thrombolysis in myocardial infarction (TIMI) trial, phase II. Circulation 1992;85:1254-64.

14 Sullivan ID, Davies DW, Sowton E. Submaximal exercise testing early after myocardial infarction. Prognostic importance of exercise induced ST segment elevation. importance of exercise induce

15 Lahiri A, Balasubramanian V, Millar Craig MW, Crawley J, Raftery EB. Exercise induced ST segment elevation. Electrocardiographic, angiographic, and scintigraphic evaluation. Br Heart $₹$ 1980;43:582-8.

16 Theroux P, Marpole DGF, Bourassa MG. Exercise stress testing in the post myocardial infarction patient. $\mathrm{Am}$ Cardiol 1983;52:664-6.

17 Davies SW, Marchant B, Lyons J, et al. Coronary lesion morphology after thrombolytic therapy in acute myocardial infarction:evidence for remodelling. $\mathcal{f} \mathrm{Am}$ Coll Cardiol 1990;16:1079-86

18 Little WC, Constantinescu M, Applegate RJ, et al. Can coronary angiography predict the site of a subsequent myocardial infarction in patients with mild-to-moderate myocardial infarction in patients with mild-to-moderate

19 Ellis SG, Topol EJ, George BS, et al. Recurrent ischaemi without warning. Analysis of risk factors for in hospital ischaemic events following successful thrombolysis with intravenous tissue plasminogen activator. Circulation 1989;80:1159-65.
20 Dillahunt PH, Miller AB. Early treadmill testing after myocardial infarction:angiographic and haemodynamic correlations. Chest 1979;76:150-9.

21 Patterson RE, Horowitz SF, Eng C. Can noninvasive exercise test criteria identify patients with left main or 3 vessel coronary disease after a first myocardial infarction. Am f Cardiol 1983;51:361-72.

22 Smith JW, Dennis CA, Gassmann A, et al. Exercise testing three weeks after myocardial infarction. Chest 1979; 75:12-6.

23 Jespersen CM, Kassis E, Edeling CJ, Masden JK. The prognostic value of maximal exercise testing soon after first myocardial infarction. Eur Heart f 1985;6:769-72.

24 Theroux P, Waters DD, Halphen C, Debaisieux JC Mizgala HF. Prognostic value of exercise testing soon Mizgala HF. Prognostic value of exercise testing soon
after myocardial infarction. $N$ Engl $f$ Med 1979;301: $341-5$

25 Norris RM, Barnaby PF, Brandt PWT, et al. Prognosis after recovery from first acute myocardial infarction: determinants of reinfarction and sudden death. $A m \mathcal{F}$ Cardiol 1984;53:408-13.

26 De Feyter PJ, Van Eenige NJ, Dighton DH, et al. Prognostic value of exercise testing, coronary angiography and left ventriculography 6-8 weeks after myocardial infarction. Circulation 1982;66:527-36.

27 Bolognese L, Sarasso G, Bongo AS, et al. Stress testing in the period after infarction. Circulation 1991;83(suppl II): $32-7$.

28 De Belder MA, Pumphrey CW, Skehan JD, et al. Relative power of clinical, exercise test, and angiographic variables in predicting clinical outcome after myocardial infarction: the Newham and tower hamlets study. $\mathrm{Br}$ Heart $\mathcal{F} 1988 ; 60: 377-89$.

29 Weld FM, Chu KL, Bigger JT, Roinitzky LM. Risk stratification with low level exercise testing 2 weeks after acute myocardial infarction. Circulation 1981;64: 306-14.

30 Peart I, Odemuyiwa O, Albers C, Hall A, Kelly C, Hall RJ. Exercise testing soon after myocardial infarction: its relation to course and outcome at one year in patients relation to course and outcome at one year in patie
aged less than 55 years. Br Heart $₹ 1989 ; 61: 231-7$.

31 Fuller CM, Raizner AE, Verani MS, et al. Early postmyocardial infarction treadmill stress testing an accurate predictor of multivessel coronary artery disease and subsequent cardiac events. Ann Intern Med 1981;94:734-9.

32 Starling MR, Crawford MH, Kennedy GT, O'Rourke RA. Exercise testing early after myocardial infarction: predictive value for subsequent unstable angina and death. Am $\mathcal{F}$ Cardiol 1980;46:909-14. 